\title{
High-Speed InSb Photodetectors on GaAs for Mid-IR Applications
}

\author{
Ibrahim Kimukin, Student Member, IEEE, Necmi Biyikli, Student Member, IEEE, \\ Tolga Kartaloğlu, Student Member, IEEE, Orhan Aytür, Senior Member, IEEE, and Ekmel Ozbay, Member, IEEE
}

\begin{abstract}
We report p-i-n type InSb-based high-speed photodetectors grown on GaAs substrate. Electrical and optical properties of photodetectors with active areas ranging from $7.06 \times 10^{-6} \mathrm{~cm}^{2}$ to $2.25 \times 10^{-4} \mathrm{~cm}^{2}$ measured at $77 \mathrm{~K}$ and room temperature. Detectors had high zero-bias differential resistances, and the differential resistance area product was $4.5 \Omega \mathrm{cm}^{2}$. At $77 \mathrm{~K}$, spectral measurements yielded high responsivity between 3 and $5 \mu \mathrm{m}$ with the cutoff wavelength of $5.33 \mu \mathrm{m}$. The maximum responsivity for $80-\mu \mathrm{m}$ diameter detectors was $1.00 \times 10^{5} \mathrm{~V} / \mathrm{W}$ at $4.35 \mu \mathrm{m}$ while the detectivity was $3.41 \times 10^{9} \mathrm{~cm} \mathrm{~Hz}^{1 / 2} / \mathrm{W}$. High-speed measurements were done at room temperature. An optical parametric oscillator was used to generate picosecond full-width at half-maximum pulses at $2.5 \mu \mathrm{m}$ with the pump at $780 \mathrm{~nm} .30-\mu \mathrm{m}$ diameter photodetectors yielded 3-dB bandwidth of $8.5 \mathrm{GHz}$ at $2.5 \mathrm{~V}$ bias.
\end{abstract}

Index Terms-High-speed, infrared, photodetector.

\section{INTRODUCTION}

$\mathbf{I}$ $\mathrm{nSb}$ is an attractive material due to its potential use in infrared photodetectors like other narrow band-gap compound semiconductors. Infrared detectors can be used in thermal imaging systems, free-space communication, and chemical agent monitoring. Although variable-bandgap $\mathrm{HgCdTe}$ has been used for many years, it is being replaced by quantum well or InSb photodetectors due to the technological difficulties [1]. InSb is the common material for the midinfrared (mid-IR) range photodetectors with the cutoff wavelength of $5.4 \mu \mathrm{m}$ at $77 \mathrm{~K}$. Ternary compounds of InSb have been used with the addition of $\mathrm{As}, \mathrm{Bi}$, or $\mathrm{Tl}$ to extend the responsivity to the far infrared region [2], [3]. Although these detector structures can be fabricated on InSb, GaSb, or InAs substrates, this method is not preferred due to low resistance of the substrate and the difficulty of thinning process for the back-illuminated focal plane arrays [4]-[6]. Instead, $\mathrm{Si}$ and GaAs substrates are more attractive even if there is a significant lattice mismatch between the substrate and epitaxial layers [7]-[9]. Although optical and electrical properties have been studied over the years, high-speed properties of InSb-based photodetectors have not been reported before. In this paper, we report the high-speed operation of InSb photodetector in the mid-IR wavelengths.

Manuscript received January 7, 2004; revised June 9, 2004. This work was supported in part by the Turkish Department of Defense under Grant KOBRA-002 and by NATO under Grant SfP971970. The work of E. Ozbay was supported by the Academy of Sciences of Turkey.

I. Kimukin and E. Ozbay are with the Department of Physics, Bilkent University, Bilkent Ankara 06800, Turkey (e-mail: kimukin@ fen.bilkent.edu.tr).

N. Biyikli, T. Kartaloğlu, and O. Aytür are with the Department of Electrical and Electronics Engineering, Bilkent University, Bilkent Ankara 06800, Turkey.

Digital Object Identifier 10.1109/JSTQE.2004.833891
The electrical and spectral responsivity characteristics at $77 \mathrm{~K}$ are also reported.

\section{DESIGN AND FABRICATION}

The epitaxial structure was grown on semi-insulating GaAs substrate by molecular beam epitaxy. A $0.1-\mu$ m-thick $\mathrm{GaSb}$ buffer layer was grown before the growth of the InSb layers. The photodetector consisted of a $0.5-\mu \mathrm{m}$-thick p+ InSb layer at the top, $1.5-\mu \mathrm{m}$-thick intrinsic InSb layer, and a $1.5-\mu \mathrm{m}$-thick $\mathrm{n}+\mathrm{InSb}$ layer at the bottom. The intrinsic layer was unintentionally doped to $2 \times 10^{15} \mathrm{~cm}^{-3}$, while the highly doped layers were doped to $10^{18} \mathrm{~cm}^{-3}$. N+ and p+ layers were doped with Tellurium and Beryllium, respectively.

The devices were fabricated by a microwave-compatible process and completed in five steps. A citric acid: $\mathrm{H}_{2} \mathrm{O}_{2}(1: 1)$ solution was used to etch the InSb. Samples were patterned and etched down to the $\mathrm{n}+\mathrm{InSb}$ layer, which was followed by a self-aligned $\mathrm{Ti}-\mathrm{Au}$ liftoff. The $\mathrm{p}+$ ohmic contacts were also achieved by Ti-Au liftoff. Except for the active area, the layers were etched down to the $\mathrm{n}+\mathrm{InSb}$ layer. This was followed by the deposition of $0.5-\mu \mathrm{m}$-thick $\mathrm{SiO}_{2}$ layer using plasma-enhanced chemical vapor deposition (PECVD) on the highly doped $n+$ layer. This layer was used as the insulating medium between the highly conductive InSb layer and the interconnect metal. The active area was covered with $\mathrm{Si}_{3} \mathrm{~N}_{4}$ for passivation and isolation. The thickness of this layer was also chosen to form an anti-reflection coating. Finally, Ti-Au metal was evaporated to form the coplanar waveguide on top of the $\mathrm{SiO}_{2}$ layer, which was essential for the high-speed operation.

Fig. 1 shows the cross section of a fabricated photodetector, while Fig. 2 shows the photograph of a $150-\mu \mathrm{m}$ diameter active area photodetector after the fabrication.

\section{EXPERIMENTAL RESULTS}

Current-voltage (I-V) characteristics of the photodetectors were measured at $77 \mathrm{~K}$ using a modular dc source/monitor unit. Photodetectors were biased between -2.0 and $+0.5 \mathrm{~V}$ at $300 \mathrm{~K}$ background. The active area of the photodetectors ranged from $7.06 \times 10^{-6} \mathrm{~cm}^{2}$ (30 $\mu \mathrm{m}$ in diameter) to $2.25 \times 10^{-4} \mathrm{~cm}^{2}$ $\left(150 \times 150 \mu \mathrm{m}^{2}\right)$. Fig. 3 shows the I-V characteristics of cooled photodetectors with 60-, 100-, and $150-\mu \mathrm{m}$ diameter. The dark current of the photodetectors gradually increases with the increasing active area. Dark current at zero biases were 48, 118, and $239 \mathrm{nA}$ for $60-, 100-$, and $150-\mu \mathrm{m}$ diameter photodetectors, respectively. 


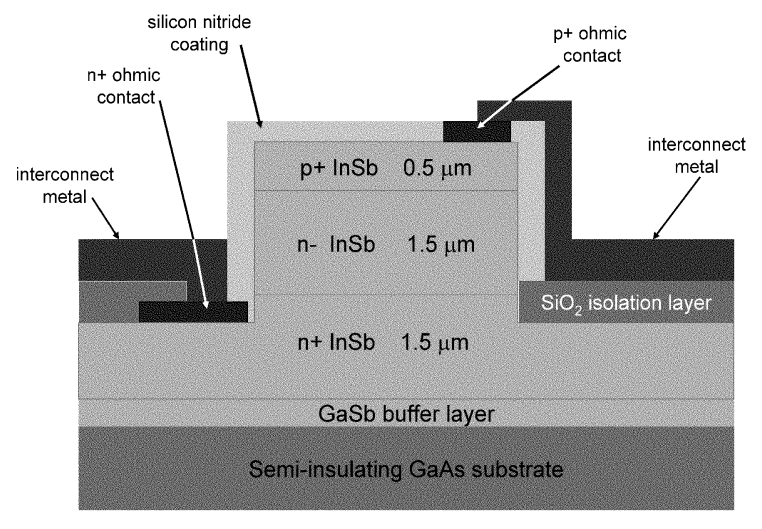

Fig. 1. Cross section of a fabricated photodetector.

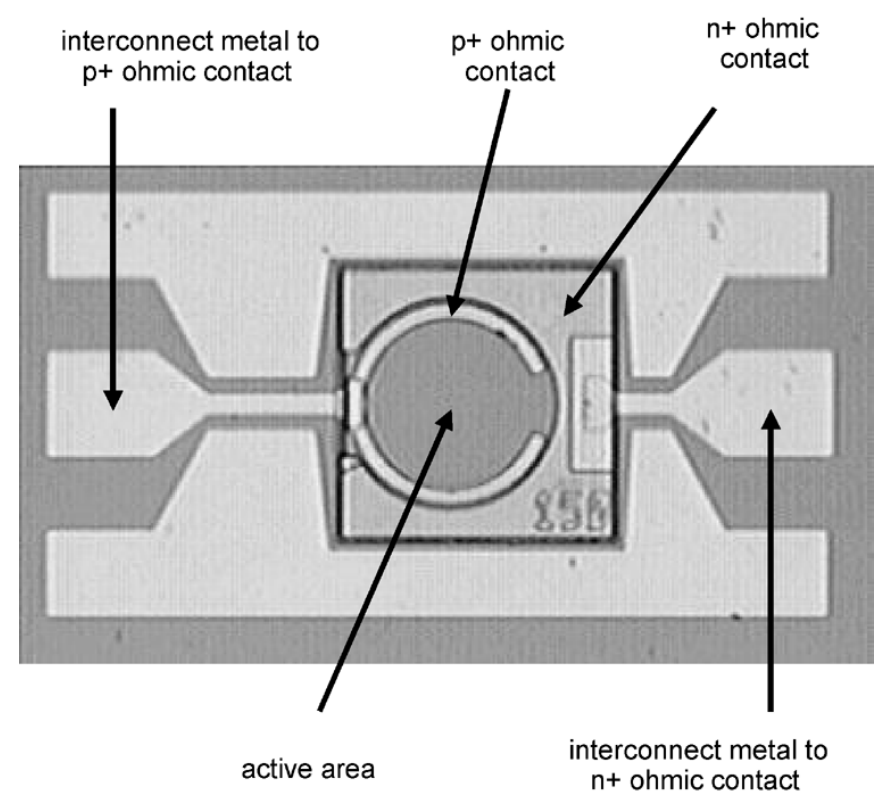

Fig. 2. Photograph of a photodetector with $150-\mu \mathrm{m}$ diameter active area.

We also calculated the differential resistances of the detectors. Our results are shown in Fig. 4(a). These results were calculated using the current-voltage values that were presented in Fig. 4. The peak position of the differential resistance shifted from $-440 \mathrm{mV}$ to $0 \mathrm{~V}$ with the decrease of the measurement temperature from $300 \mathrm{~K}$ to $77 \mathrm{~K}$ [9]. Fig. 4(b) shows the area dependence of the zero-bias differential resistance $\left(\mathrm{R}_{0}\right)$. $\mathrm{R}_{0}$ had an exponential dependence on the active area. Resistance-area product $\left(\mathrm{R}_{0} \mathrm{~A}\right)$ for the largest area photodetectors was $4.5 \Omega \mathrm{cm}^{2}$, while it was $7.8 \times 10^{-1} \Omega \mathrm{cm}^{2}$ for the smallest photodetectors. These values are comparable with the results of other InSb photodetectors grown on $\mathrm{GaAs}$ or $\mathrm{Si}$ substrates. Dark current density analysis as a function of area showed that the surface diffusion and generation current was dominant for low reverse bias values [10]. The $\mathrm{R}_{0} \mathrm{~A}$ product was limited by these currents for small area detectors. A better passivation should be used or the temperature must be lowered to eliminate the surface currents.

The optical characteristics of the detectors were measured using a computer-controlled characterization system. Samples were mounted on an alumina substrate with thermally conductive epoxy. Electrical connections were made with wire
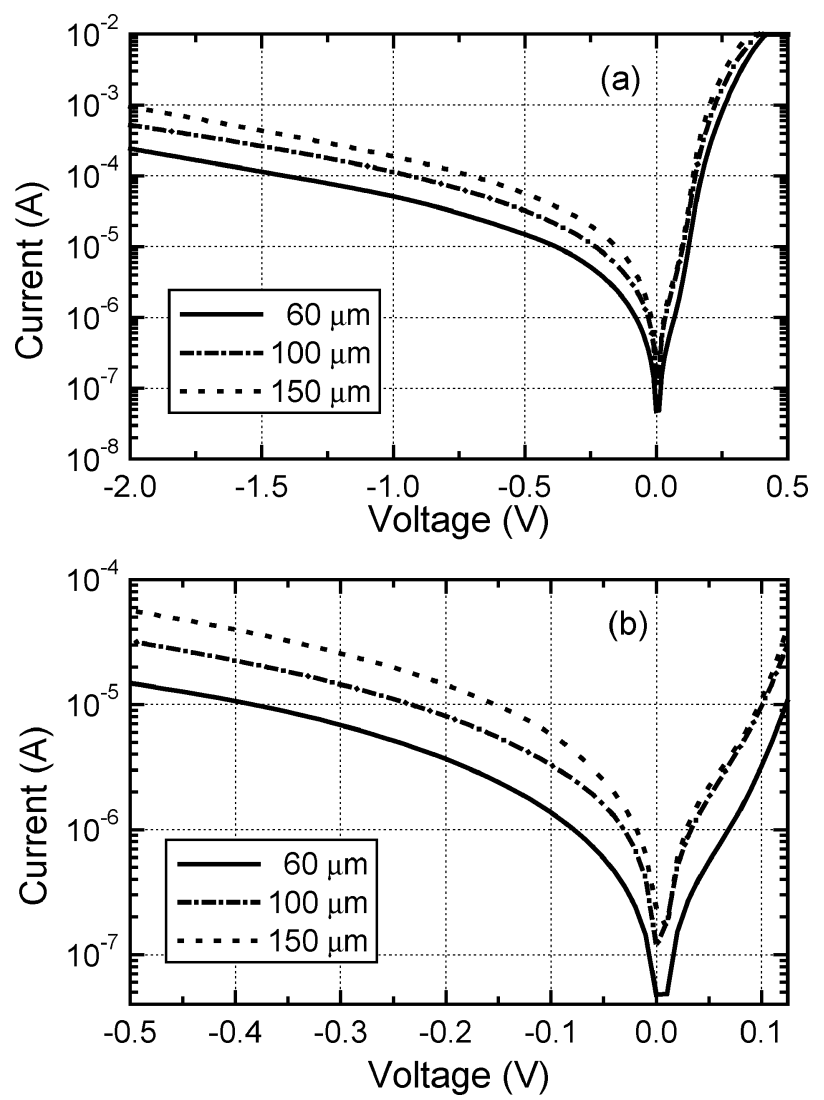

Fig. 3. (a) Measured current-voltage characteristics of 60-, 100-, and 150- $\mu \mathrm{m}$ diameter photodetectors at $77 \mathrm{~K}$. (b) Detailed results around zero bias.
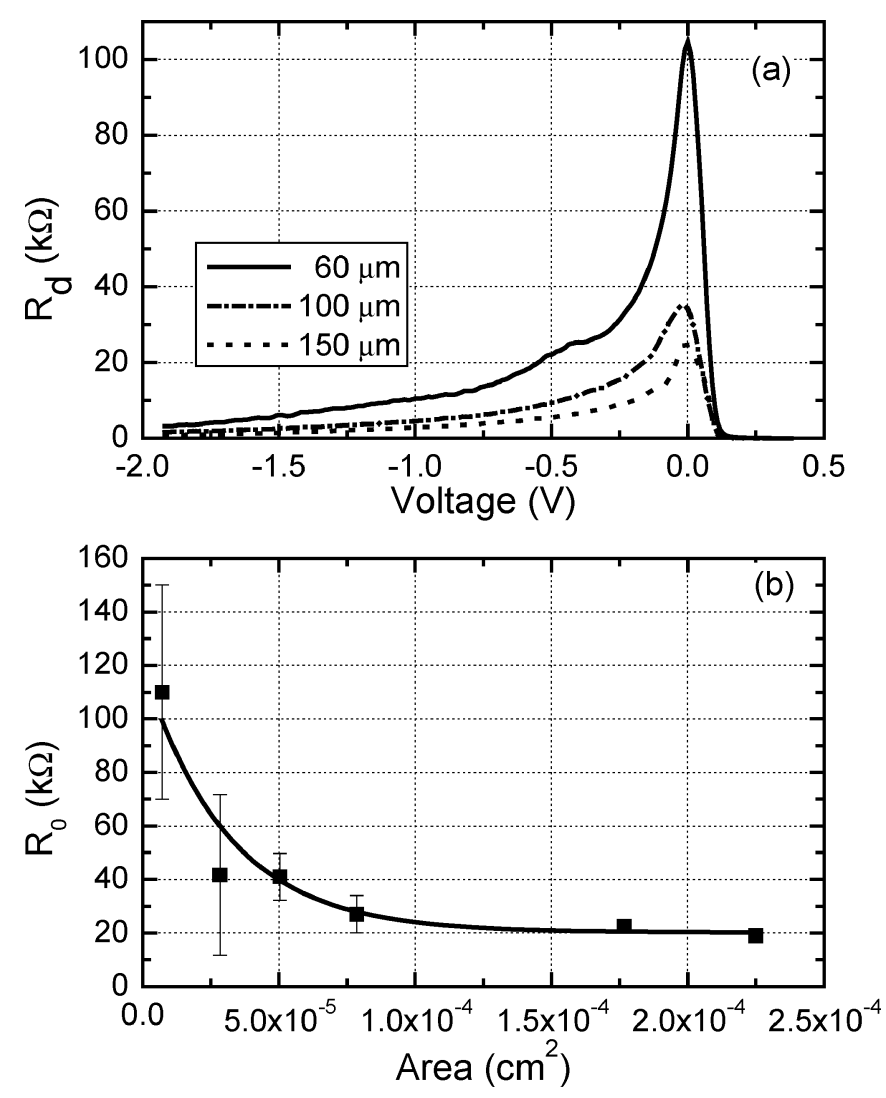

Fig. 4. (a) Calculated differential resistance $\left(R_{d}\right)$ as a function of bias voltage. (b) Zero bias differential resistance $\left(R_{0}\right)$ as a function of detector area. 


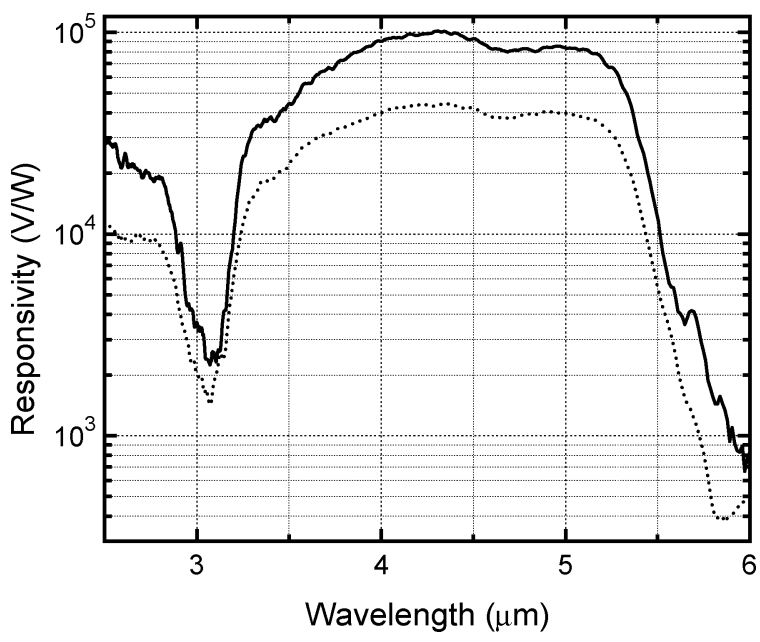

Fig. 5. Results of the spectral responsivity measurements are shown for 80(solid line) and 60- $\mu \mathrm{m}$ (dotted line) diameter photodetector.

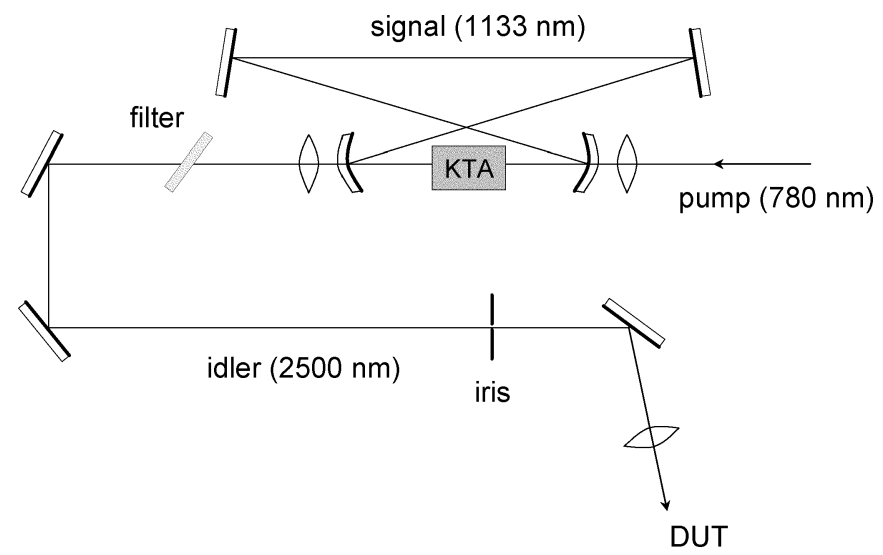

Fig. 6. Schematic diagram of the optical parametric oscillator.

bonding. A sample was placed in a dewar with $\mathrm{ZnSe}$ optical window for characterization. A blackbody at $774 \mathrm{~K}$ was used as the infrared (IR) light source. The detector signal and noise were measured using a low-noise preamplifier and a lock-in amplifier, while the IR light was chopped at $680 \mathrm{~Hz}$. The spectral measurements were made in the 2.5 - to $6.0-\mu \mathrm{m}$ wavelength range using an Oriel MIR-8000 FTIR system and a pyroelectric reference detector. Fig. 5 shows the $77 \mathrm{~K}$ spectral response of 80- (solid line) and 60- $\mu \mathrm{m}$ (dotted line) diameter photodetectors. The cutoff wavelength (where the responsivity dropped to half of the maximum) was $5.33 \mu \mathrm{m}$. This corresponded to an energy bandgap of $0.23 \mathrm{eV}$, which was in good agreement with the theoretical value at $77 \mathrm{~K}$.

Responsivity decreased sharply after the cutoff wavelength and it was two orders of magnitude below the maximum value at $6.0 \mu \mathrm{m}$. In the responsivity spectrum, two dips at 3.1 and $4.6 \mu \mathrm{m}$ can be seen easily. This was due to the absorption peaks of ice in the IR region [11]. Due to leakage in the vacuum, water vapor accumulated on the detector, forming ice, which degraded the performance of the detectors. Maximum responsivities of the detectors were $1.00 \times 10^{5} \mathrm{~V} / \mathrm{W}$ and $4.41 \times 10^{4} \mathrm{~V} / \mathrm{W}$, respectively at $4.35 \mu \mathrm{m}$. Both photodetectors had nearly equal current responsivity of 1.8 and $1.7 \mathrm{~A} / \mathrm{W}$, respectively, which corresponds to $49 \%$ quantum efficiency. We also measured high detectivities
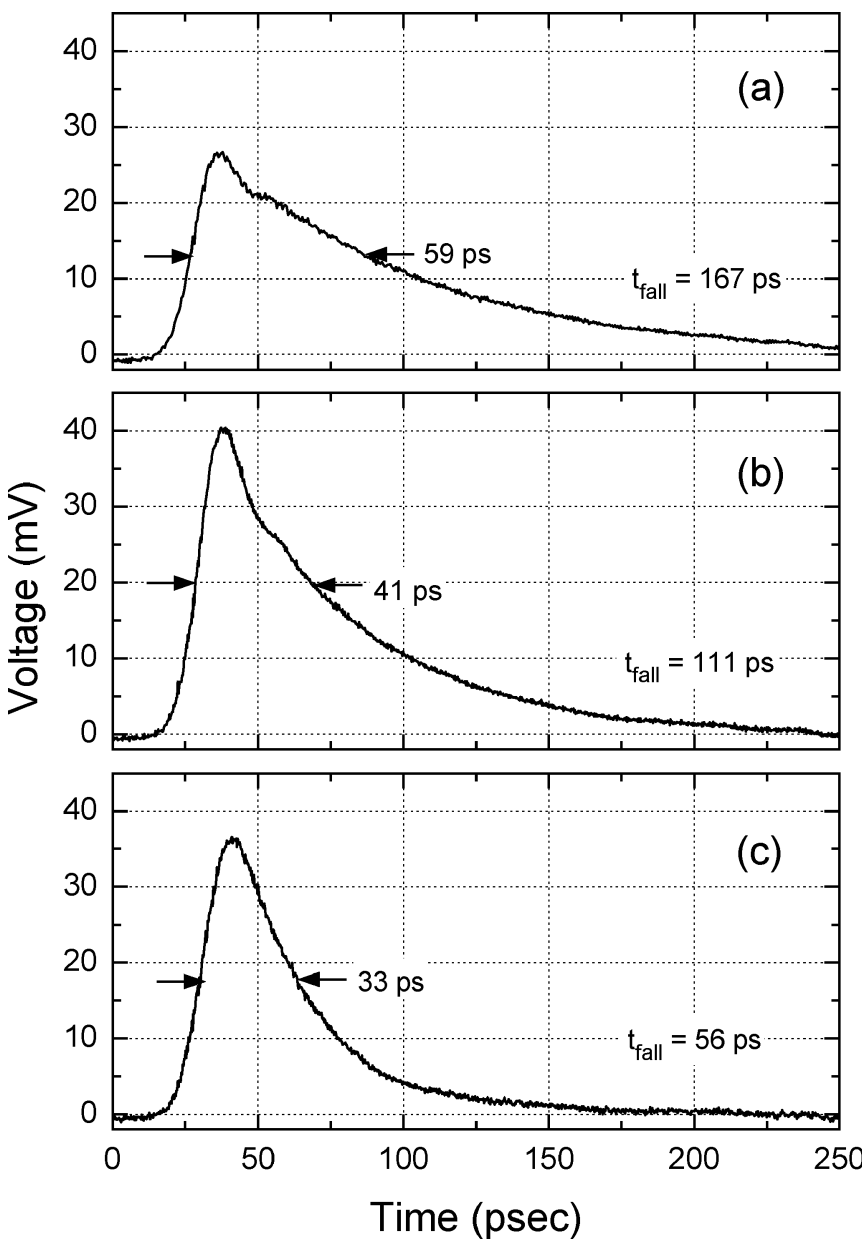

Fig. 7. Temporal response of a $30-\mu \mathrm{m}$ diameter detector under (a) $0.5-$, (b) $1.0-$, and (c) $2.5-\mathrm{V}$ bias.

for the photodetectors. Peak detectivities of the photodetectors were $3.41 \times 10^{9} \mathrm{~cm} \mathrm{~Hz}^{1 / 2} / \mathrm{W}$ for the $80-\mu \mathrm{m}$ diameter detector and $7.98 \times 10^{9} \mathrm{~cm} \mathrm{~Hz}^{1 / 2} / \mathrm{W}$ for the $60-\mu \mathrm{m}$ diameter detector.

Due to a lack of suitable measurement setup, high-speed measurements had to be done at room temperature. Picosecond full-width at half maximum (FWHM) pulses were generated using a $\mathrm{KTiOAsO}_{4}$ (KTA)-based optical parametric oscillator $(\mathrm{OPO})$ at $2500 \mathrm{~nm}$. Fig. 6 shows the experimental setup of the OPO. The OPO consisted of an optical resonator with four mirrors that were highly reflective at the signal wavelength and a 20-mm-long KTA crystal that has been cut for noncritical phase matching along the $\theta=90^{\circ}$ and $\phi=0^{\circ}$ direction. Type-II polarization geometry was employed to achieve parametric creation [12]. OPO was pumped by a mode-locked Ti:Sapphire laser operating at 780-nm wavelength with 150 femtosecond FWHM pulses at a 76-MHz repetition rate.

Phase matching was achieved yielding a signal at $1133 \mathrm{~nm}$ and an idler at around $2500 \mathrm{~nm}$. At the output of the OPO the pump and the signal were filtered out. The idler signal was then focused on the active area of the photodetectors using an iris and infrared lens [13]. These pulses had a 1-ps FWHM.

The temporal response of the photodetectors was measured on a 50-GHz sampling scope and the detectors were biased using a $40-\mathrm{GHz}$ bias tee [14]. Temporal responses of 30- and $60-\mu \mathrm{m}$ diameter photodetectors were measured as a function 


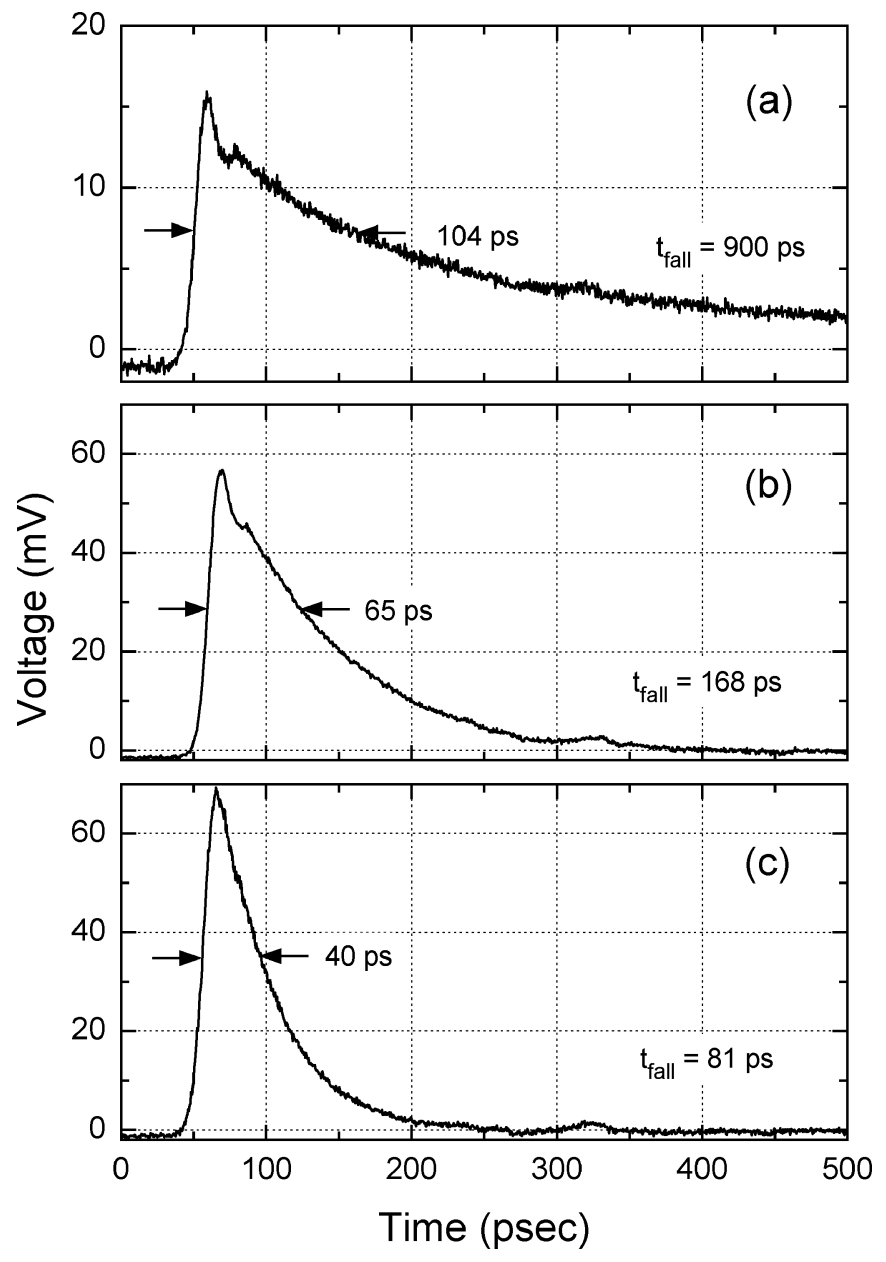

Fig. 8. Temporal response of a $60-\mu \mathrm{m}$ diameter detector under (a) 0.5-, (b) $1.0-$, and (c) $2.5-\mathrm{V}$ bias.

of reverse bias. Without bias, the responses had long tails. This tail was due to the diffusion of carriers in the intrinsic region, which could not be depleted without bias at room temperature. With the application of bias voltage, we observed a reduction of the FWHM of the detector responses. At $0.5 \mathrm{~V}$ bias, the FWHM values were measured as 59 and 104 ps for 30- and $60-\mu \mathrm{m}$ diameter photodetectors, respectively. After $1-\mathrm{V}$ bias, FWHM values decreased linearly with voltage up to $2.5 \mathrm{~V}$. Measured FWHM values for the detectors biased with 1.0 and $2.5 \mathrm{~V}$ were 41 and $33 \mathrm{ps}$ for $30-\mu \mathrm{m}$ and 65 and 40 ps for $60 \mu \mathrm{m}$. Figs. 7 and 8 show the temporal response of the 30- and $60-\mu \mathrm{m}$ diameter photodetectors under $0.5-$, $1.0-$, and $2.5-\mathrm{V}$ biases. For each detector, both the FWHM and the fall time decreased as we increased the bias voltage. Frequency responses of the detectors were calculated using a fast Fourier transform (FFT). Fig. 9(a) and (b) shows the calculated FFT results of the detectors as a function of bias voltage. Fig. 9(c) shows the 3-dB bandwidth of the detectors as a function of bias. The linear increase in bandwidth with the bias can be seen easily beyond $1.0 \mathrm{~V}$ bias. The maximum bandwidth measured for the $30-\mu \mathrm{m}$ diameter detector was 8.5 GHz. We expect similar or better high-speed responses when the photodetectors are cooled to $77 \mathrm{~K}$. The detector active area should be depleted easier and the diffusion related
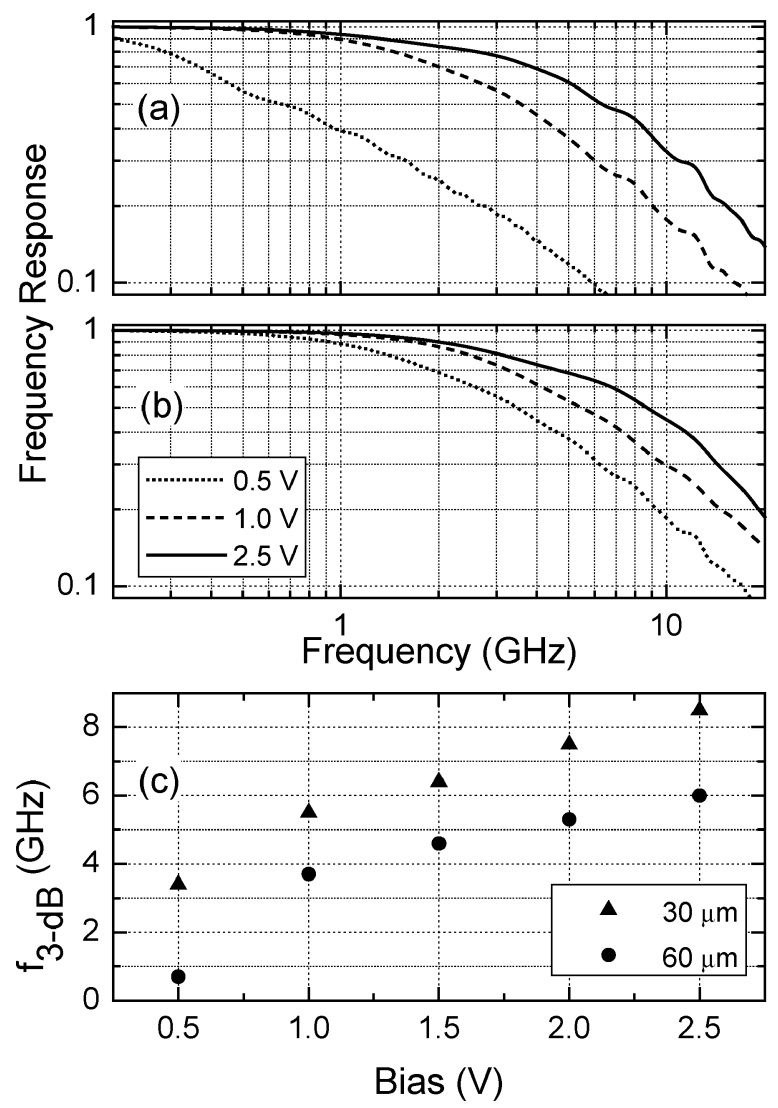

Fig. 9. FFT of the temporal responses of the photodetectors. Results for (a) 60- $\mu \mathrm{m}$ diameter and (b) 30- $\mu \mathrm{m}$ diameter photodetectors as a function of bias are shown. (c) 3-dB bandwidth of the 30- and 60- $\mu \mathrm{m}$ diameter photodetectors as a function of applied bias.

slow responses can be eliminated. Such high-speed infrared photodetectors can be used for optical heterodyne detection and microwave mixing, infrared laser inspection, and free-space communication [15], [16]. It is known that mid-IR and far-IR wavelength region (3-5 $\mu \mathrm{m}$, and $8-14 \mu \mathrm{m}$ ) are better than visible or near-infrared regions in terms of transmission and background noise [17].

\section{CONCLUSION}

We have demonstrated the high-speed operation of the InSb-based p-i-n photodetectors in the mid-IR. The detectors showed 33-ps FWHM at $2.5 \mathrm{~V}$ bias, corresponding to a 3-dB bandwidth of $8.5 \mathrm{GHz}$. At low bias voltages, the detectors had 59-ps FWHM, which corresponded to a bandwidth of $3.4 \mathrm{GHz}$. Responsivity measurements showed that the detectors had high responsivity in the mid-IR where the maximum value was $1.00 \times 10^{5} \mathrm{~V} / \mathrm{W}$ at $4.35 \mu \mathrm{m}$ for $60-\mu \mathrm{m}$ diameter detectors.

\section{ACKNOWLEDGMENT}

The authors would like to thank C. Besikci, S. Ozer, and O. Orkun Cellek for their contribution to this work during the testing of the photodetectors.

\section{REFERENCES}

[1] A. Rogalski, "Quantum well photoconductors in infrared detector technology," J. Appl. Phys., vol. 93, pp. 4355-4391, 2003. 
[2] J. J. Lee, J. D. Kim, and M. Razeghi, "Growth and characterization of InSbBi for longwavelength infrared photodetectors," Appl. Phys. Lett., vol. 70, pp. 3266-3268, 1997.

[3] J. D. Kim, S. Kim, D. Wu, J. Wojkowski, J. Xu, J. Piotrawski, E. Bigan, and M. Razeghi, "8-13 $\mu \mathrm{m}$ InAsSb heterojunction photodiode operating at near room temperature," Appl. Phys. Lett., vol. 67, pp. 2645-2647, 1995.

[4] T. Ashley, A. B. Dean, C. T. Elliott, C. F. McConville, and C. R. Whitehouse, "Molecular-beam growth of homoepitaxial InSb photovoltaic detectors," Electron. Lett., vol. 24, pp. 1270-1272, 1988.

[5] A. Rakovska, V. Berger, X. Marcadet, B. Vinter, G. Glestre, T. Oksenhendler, and D. Kaplan, "Room temperature InAsSb photovoltaic midinfrared detector," Appl. Phys. Lett., vol. 77, pp. 397-399, 2000.

[6] D. T. Cheung, A. M. Andrews, E. R. Gertner, G. M. Williams, J. E. Clarke, J. G. Pasko, and J. T. Longo, "Backside-illuminated $\mathrm{InAs}_{1-\mathrm{x}} \mathrm{Sb}_{\mathrm{x}}-\mathrm{InAs}$ narrow-band photodetectors," Appl. Phys. Lett., vol. 30, pp. 587-589, 1977.

[7] S. Ozer and C. Besikci, "Assessment of InSb photodetectors on Si substrate," J. Phys. D: Appl. Phys., vol. 36, pp. 559-563, 2003.

[8] C. Besikci, S. Ozer, C. V. Hoof, L. Zimmermann, J. John, and P. Merken, "Characteristics of In $\mathrm{As}_{0.8} \mathrm{Sb}_{0.2}$ photodetectors on GaAs substrate," Semicond. Sci. Technol., vol. 16, pp. 992-996, 2001.

[9] I. Kimukin, N. Biyikli, and E. Ozbay, "InSb high-speed photodetectors grown on GaAs substrate," J. Appl. Lett., vol. 94, pp. 5414-5416, 2003.

[10] A. Tevke, C. Besikci, C. V. Hoof, and G. Borghs, "InSb infrared p-i-n photodetectors grown on GaAs coated Si substrate by molecular beam epitaxy," Solid-State Electron., vol. 42, pp. 1039-1044, 1998.

[11] S. G. Warren, "Optical constants of ice from ultraviolet to the microwave," Appl. Opt., vol. 23, pp. 1206-1225, 1984.

[12] T. Kartaloğlu and O. Aytür, "Femtosecond self-doubling optical parametric oscillator based on $\mathrm{KTiOAsO}_{4}$," IEEE J. Quantum. Electron., vol. 39, pp. 65-67, Jan. 2003.

[13] I. Kimukin, E. Ozbay, N. Biyikli, T. Kartaloğlu, O. Aytür, S. Ünlü, and G. Tuttle, "High-speed GaAs-based resonant-cavity-enhanced $1.3 \mu \mathrm{m}$ photodetector," Appl. Phys. Lett., vol. 77, pp. 3890-3892, 2000.

[14] I. Kimukin, N. Biyikli, B. Butun, O. Aytur, S. Ünlü, and E. Ozbay, "InGaAs based high performance p-i-n photodiodes," IEEE Photon. Technol. Lett., vol. 14, pp. 366-368, 2002.

[15] E. R. Brown, K. A. McIntosh, F. W. Smith, and M. J. Manfa, "Coherent detection with GaAs/AlGaAs multiple quantum well structure," Appl. Phys. Lett., vol. 62, pp. 1513-1515, 1993.

[16] H. C. Liu, G. E. Jenkins, E. R. Brown, K. A. McIntosh, K. B. Nichols, and M. J. Manfra, "Optical heterodyne detection and microwave rectification up to $26 \mathrm{GHz}$ using quantum well infrared photodetectors," IEEE Electron. Device Lett., vol. 16, pp. 253-255, 1995.

[17] H. Manor and S. Arnon, "Performance of an optical wireless communication as a function of wavelength," Appl. Opt., vol. 42, pp. 4285-4294, 2003.

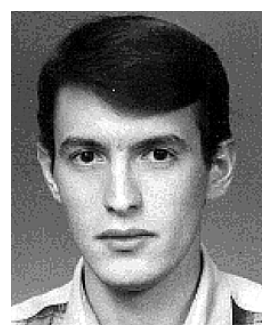

Ibrahim Kimukin ( $\left.\mathrm{S}^{\prime} 00\right)$ was born in Edirne, Turkey, in 1976. He received the B.S. degree from Middle East Technical University, Ankara, Turkey, in 1997, and the M.S. degree from Bilkent University, Ankara, in 1999. He is currently working toward the Ph.D. degree at the same university.

In his research, he designed, fabricated and tested photodetectors grown with III-V semiconductor materials such as GaAs, AlAs, AlGaAs, InGaAs, InAlAs, InP, InGaAsP, InAs, InSb, and GaSb. He also worked on wide-bandgap materials such as $\mathrm{GaN}$, and AlGaN for high-performance solar blind photodetectors. He has (co)authored more than 30 journal papers and conference proceedings.

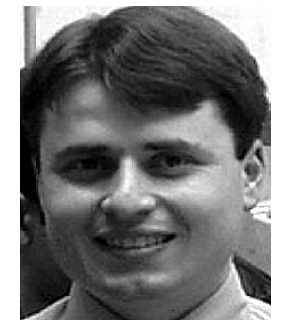

Necmi Biyikli (S'01) was born in Utrecht, The Netherlands, in 1974. He received the B.S. and M.S. degrees in electrical and electronics engineering from Bilkent University, Ankara, Turkey, in 1996 and 1998, respectively. Currently he is working toward the $\mathrm{Ph} . \mathrm{D}$. degree at the same institution.

$\mathrm{He}$ has worked with AlGaAs, InAlGaAs/InP, $\mathrm{InSb} / \mathrm{InAs}$, and GaN/AlGaN material systems. During his Ph.D. research, he has (co)authored more than 30 refereed journal articles and conference proceedings. His research interests include design, fabrication, and characterization of high-performance photodetectors, high-speed optoelectronic devices, solar-blind UV photodiodes, III-nitride alloys, wide bandgap semiconductors, and physics and applications of nanostructures, nanoscale photonics, and electronic devices.

Tolga Kartaloğlu (S'90) received the B.Sc. degree from the Department of Electrical and Electronics Engineering, Middle East Technical University, Ankara, Turkey, in 1994, and the M.Sc. and Ph.D. degrees from the Department of Electrical and Electronics Engineering, Bilkent University, Ankara, in 1996 and 2002, respectively.

His research interests include lasers, nonlinear optics, wavelength conversion, and optical parametric oscillators and amplifiers.

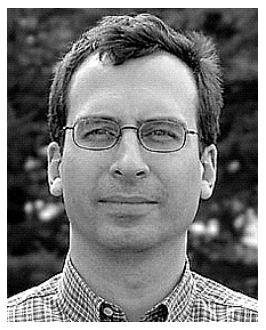

Orhan Aytür (M'94-SM'00) was born in Ankara, Turkey, in 1965. He received the B.S. degree in electrical engineering from Middle East Technical University, Ankara, Turkey, in 1986, and the M.S. and $\mathrm{Ph} . \mathrm{D}$. degrees in electrical engineering from Northwestern University, Evanston, IL, in 1988 and 1991.

He worked as a Laser Scientist at Fibertek, Inc., and as a Research Associate at the University of New Mexico in 1991 and 1992. He joined the Department of Electrical Engineering, Bilkent University, Ankara, in 1993, where he is presently a Professor. His research interests include nonlinear frequency conversion of lasers, quantum optics, and high-performance photodetectors.

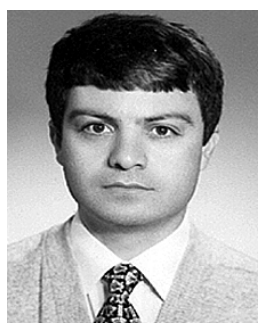

Ekmel Ozbay (M'98) was born on March 25, 1966, in Ankara, Turkey. He received the B.S. degree in electrical engineering from the Middle East Technical University, Ankara, in 1983 and the M.S. and Ph.D. degrees in electrical engineering from Stanford University, Stanford, CA, in 1989 and 1992.

From 1992 to 1994, he worked as a Scientist at the DOE Ames National Laboratory, Iowa State University, in the area of photonic band gap materials. He joined the faculty of the Physics Department, Bilkent University, Ankara, in December 1994, where he is currently a Full Professor. His research includes GaN-based devices, photonic crystals, silicon micromachining, and high-speed optoelectronics. He has authored or coauthored more than 160 articles in scientific journals, conference proceedings, and books.

Dr. Ozbay is the 1997 recipient of the Adolph Lomb Medal of Optical Society of America. He is currently acting as a Topical Editor for Optics Letters. 